\title{
Water-sensitive multicolor luminescence in lanthanide-organic framework for anti-counterfeiting
}

\author{
Tifeng Xia†, Wenqian $\mathrm{Cao}^{\dagger}$, Yuanjing Cui*, Yu Yang and Guodong Qian*
}

The development of high-level anti-counterfeiting techniques is of great significance in economics and security issues. However, intricate reading methods are required to obtain multi-level information stored in different colors, which greatly limits the application of anti-counterfeiting technology on solving real world problems. Herein, we realize multicolor information anti-counterfeiting under simply external stimulation by utilizing the functional groups and multiple emission centers of lanthanide metal organic framework (Ln-MOFs) to tune luminescence color. Water responsive multicolor luminescence represented by both the tunable color from red to blue within the visible region and high sensitive responsivity has been achieved, owing to the increased nonradiative decay pathways and enhanced Eu ${ }^{3+}$-to-ligand energy back transfer. Remarkably, information hidden in different colors needs to be read with a specific water content, which can be used as an encryption key to ensure the security of the information for high-level anti-counterfeiting.

Keywords: metal-organic framework; multicolor luminescence; anti-counterfeiting

Xia TF, Cao WQ, Cui YJ, Yang Y, Qian GD. Water-sensitive multicolor luminescence in lanthanide-organic framework for anticounterfeiting. Opto-Electron Adv 4, 200063 (2021).

\section{Introduction}

The rampant appearance of counterfeit products has caused tremendous economic losses to customers and copyright owners, and the phenomena from fake medicines to fake military equipment have made it clear that the counterfeit business has become an economic, human health and national security issue ${ }^{1-3}$. In order to solve this issue, anti-counterfeiting techniques have been developed, in which a very effective and convenient method is to put anti-counterfeiting luminescent labels on the products that need to be protected ${ }^{4-6}$. Traditionally, reading out the real information hidden in the fluorescent material requires ultraviolet (UV) excitation. Nev- ertheless, the unicolor anti-counterfeiting method relies on simple labels produced during use, and its low complexity means that these labels can be easily copied by counterfeiters ${ }^{7}$. Meanwhile, although more complex labels with multicolor and multimodal luminescence have proven to be effective means for high-level anti-counterfeiting, these multicolor or multimodal labels strongly depend on the alternating use of expensive lasers or high-power lasers as the key to read out information ${ }^{8-12}$. This is not an anti-counterfeiting method that can be universally applied to many products on the market. Therefore, a new kind of high-level anti-counterfeiting luminescent materials with multicolor luminescence and

State Key Laboratory of Silicon Materials, Cyrus Tang Center for Sensor Materials and Applications, School of Materials Science and Engineering, Zhejiang University, Hangzhou 310027, China.

tThese authors contributed equally to this work.

"Correspondence: YJ Cui, E-mail: cuiyj@zju.edu.cn; GD Qian, E-mail: gdqian@zju.edu.cn

Received: 6 August 2020; Accepted: 6 December 2020; Published: 25 August 2021

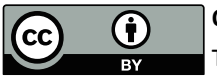

Open Access This article is licensed under a Creative Commons Attribution 4.0 International License.

To view a copy of this license, visit http://creativecommons.org/licenses/by/4.0/.

(C) The Author(s) 2021. Published by Institute of Optics and Electronics, Chinese Academy of Sciences. 
handy read out model should be explored as an alternative.

As a novel type of multifunctional luminescent materials, metal-organic frameworks (MOFs), constructed by metal ions/clusters and organic ligands through coordinate bonds, have received tremendous attention due to their predicable structures, high porosity, and easily tailorable functions ${ }^{13-23}$. The multi-photon units of MOFs offer it multiple emission centers and tunable energy transmission processes, thus achieving multicolor light emission $^{24-27}$. Especially, the lanthanide metal organic framework (Ln-MOFs), as a subclass of MOFs, can greatly improve the separation of dual-emission peaks from the ligand and metal ions due to the narrow peak emission of lanthanide ions, providing more possibility for the realization of coordinated multicolor changes ${ }^{28-30}$. On the other hand, the tunability of MOFs with organic linkers is of important features due to the unlimited possibility to design multi-functional organic linkers, which can be a point to design the key reading out information $^{31}$. Accordingly, the suitable design and utilization of Ln-MOFs could offer an innovative scheme for the development of multicolor anti-counterfeiting tags under external stimuli.

Considering that chemical anti-counterfeiting methods can be an efficient way for the encryption of information, herein, we present to utilize the multiple centers of MOFs to develop multicolor luminescence under simply external stimuli by precisely designing the synergy emission between metal ions and ligands. The introduction of functional groups as guest interactive sites can interact with external stimuli (the key to analyze information) on the organic ligand, and change the nonradiative decay pathways and energy transfer of MOFs, affecting the final luminescent color. As a proof-of-concept experiment, we design to use the most commonly used water in nature as the key to change the luminescent state of multiple emission centers of a lanthanide MOF, $\mathrm{Eu}(\mathrm{BDC}$ $\left.\mathrm{NH}_{2}\right)\left(\mathrm{BDC}-\mathrm{NH}_{2}=2\right.$-aminoterephthalate), and thus obtain multicolor luminescence. Benefiting from the suitable stability of $\mathrm{Eu}\left(\mathrm{BDC}-\mathrm{NH}_{2}\right)$ in water and hydrogenbond interaction between - $\mathrm{NH}_{2}$ group and water molecule, as-synthesized $\mathrm{Eu}\left(\mathrm{BDC}-\mathrm{NH}_{2}\right)$ exhibits gradually enhanced ligand-based luminescence and quenched lanthanide emission with the increasing the water content. And, crucially, the inverse change of emission intensity from ligands and lanthanide ions enables $\mathrm{Eu}\left(\mathrm{BDC}-\mathrm{NH}_{2}\right)$ to generate colorful luminescence under different water content, and the specific content of water can be used as the key to add the level of encryption for the anti-counterfeiting ink. Meanwhile, the variable luminescence colors that are visible to the naked eye guarantee the feasibility of $\mathrm{Eu}\left(\mathrm{BDC}-\mathrm{NH}_{2}\right)$ for in situ visualization of the multicolor information.

\section{Experimental section}

Synthesis of $\mathrm{Eu}\left(\mathrm{BDC}-\mathrm{NH}_{2}\right), \quad \mathrm{Tb}\left(\mathrm{BDC}-\mathrm{NH}_{2}\right)$ and $\mathrm{Gd}\left(\mathrm{BDC}-\mathrm{NH}_{2}\right): \mathrm{Eu}\left(\mathrm{BDC}-\mathrm{NH}_{2}\right)$ was synthesized by the solvothermal method. A mixture of $\mathrm{Eu}\left(\mathrm{NO}_{3}\right)_{3} \cdot 6 \mathrm{H}_{2} \mathrm{O}$ (323.4 mg, $0.725 \mathrm{mmol}$ ), 2-aminoterephthalic acid $\left(\mathrm{H}_{2} \mathrm{BDC}-\mathrm{NH}_{2}, 131.3 \mathrm{mg}, 0.725 \mathrm{mmol}\right)$, 2-fluorobenzoic acid (2-FBA, $812.6 \mathrm{mg}, 5.8 \mathrm{mmol})$, DMF ( $36.5 \mathrm{~mL}), \mathrm{H}_{2} \mathrm{O}$ ( $3 \mathrm{~mL}$ ), and $\mathrm{HNO}_{3}(2 \mathrm{~mL}, 3.5 \mathrm{M}$ in DMF) was added to a $100 \mathrm{~mL}$ Teflon-lined stainless steel reactor, heated at 110 ${ }^{\circ} \mathrm{C}$ for $60 \mathrm{~h}$, and then slowly cooled to room temperature. The colorless crystals of $\mathrm{Eu}\left(\mathrm{BDC}-\mathrm{NH}_{2}\right)$ were collected and washed with dimethylformamide (DMF). Elemental analysis: Anal. Calcd. for $\left(\mathrm{Me}_{2} \mathrm{NH}_{2}\right)_{2}\left[\mathrm{Eu}_{6}\left(\mu_{3}-\right.\right.$ $\left.\mathrm{OH})_{8}\left(\mathrm{BDC}-\mathrm{NH}_{2}\right)_{6}\left(\mathrm{H}_{2} \mathrm{O}\right)_{6}\right] \cdot 5 \mathrm{DMF} \quad\left(\mathrm{C}_{67} \mathrm{H}_{101} \mathrm{Eu}_{6} \mathrm{~N}_{13} \mathrm{O}_{43}\right.$, 2688.39): C 29.93, H 3.76, N 6.76; found: C 30.56, H 3.72, $\mathrm{N}$ 6.67. $\mathrm{Tb}\left(\mathrm{BDC}-\mathrm{NH}_{2}\right)$ and $\mathrm{Gd}\left(\mathrm{BDC}-\mathrm{NH}_{2}\right)$ were synthesized similarly to $\mathrm{Eu}\left(\mathrm{BDC}-\mathrm{NH}_{2}\right)$ by using $\mathrm{Tb}\left(\mathrm{NO}_{3}\right)_{3} \cdot 6 \mathrm{H}_{2} \mathrm{O}$ and $\mathrm{Gd}\left(\mathrm{NO}_{3}\right)_{3} \cdot 6 \mathrm{H}_{2} \mathrm{O}$ instead of $\mathrm{Eu}\left(\mathrm{NO}_{3}\right)_{3} \cdot 6 \mathrm{H}_{2} \mathrm{O}$, respectively. X-ray crystal data for $\mathrm{Eu}\left(\mathrm{BDC}-\mathrm{NH}_{2}\right)$ show: $\mathrm{C}_{67} \mathrm{H}_{101} \mathrm{Eu}_{6} \mathrm{~N}_{13} \mathrm{O}_{43}, M w=2688.39$, $0.2 \times 0.2 \times 0.2 \mathrm{~mm}^{3}$, Cubic, $F m \overline{3} m, a=b=c=21.7579 \AA$ $\left(1 \AA=10^{-10} \mathrm{~m}\right), Z=4, T=296 \mathrm{~K}, \mathrm{~F}(000)=4120,26525$ reflections, 9234 independent reflections, $R_{\text {int }}=0.0444$, $R_{1}=0.0391, w R_{2}=0.1082, \mathrm{GOF}=1.006$.

[CCDC 1500928 contains the supplementary crystallographic data for this paper. These data can be obtained free of charge from The Cambridge Crystallographic Data Center via www.ccdc.cam.ac.uk/data_request/cif.]

\section{Results and discussion}

The MOF $\mathrm{Eu}\left(\mathrm{BDC}-\mathrm{NH}_{2}\right)$ was synthesized through the solvothermal reaction between $\mathrm{Eu}\left(\mathrm{NO}_{3}\right)_{3} \cdot 6 \mathrm{H}_{2} \mathrm{O}$ and 2aminoterephthalic acid $\left(\mathrm{H}_{2} \mathrm{BDC}-\mathrm{NH}_{2}\right)$ in mixed solvents of $\mathrm{N}, \mathrm{N}$-DMF and water using 2-fuorobenzoic acid (2FBA) as a cluster directing agent according to the method reported by Eddaoudi et al ${ }^{32,33}$. $\mathrm{Eu}\left(\mathrm{BDC}-\mathrm{NH}_{2}\right)$ was formulated as $\left(\mathrm{Me}_{2} \mathrm{NH}_{2}\right)_{2}\left[\mathrm{Eu}_{6}\left(\mu_{3}-\mathrm{OH}\right)_{8}\left(\mathrm{BDC}-\mathrm{NH}_{2}\right)_{6}\right.$ $\left.\left(\mathrm{H}_{2} \mathrm{O}\right)_{6}\right]$.5DMF based on single-crystal X-ray diffraction studies, elemental microanalysis, Fourier transform infrared spectroscopy (FT-IR), and thermogravimetric analysis (TGA) (Figs. S1-S2, Supplementary information). The phase purity of the bulk material was further 

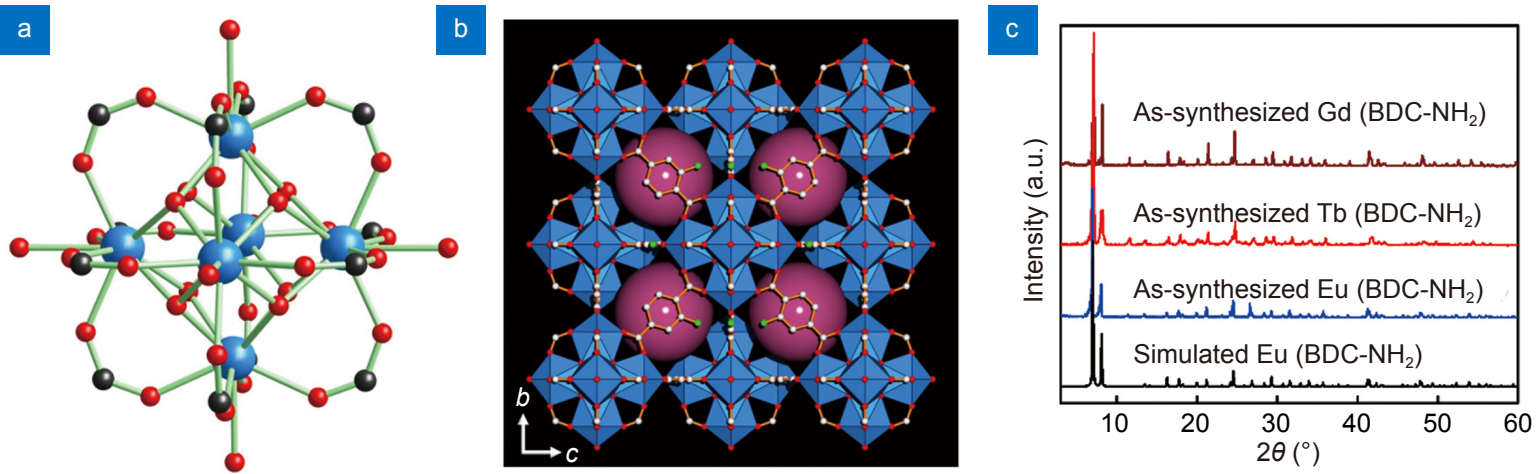

Fig. 1 | (a) Structure of 12-connected hexanuclear Eu cluster $\left[\mathrm{Eu}_{6}\left(\mu_{3}-\mathrm{OH}\right)_{8}\left(\mathrm{CO}_{2}\right)_{12}\right]$. Eu, blue; C, black; O, red. (b) Crystal structure of Eu(BDC$\mathrm{NH}_{2}$ ) viewed along the a axis. Eu, blue polyhedra; C, gray; O, red; $\mathrm{N}$, blue; $\mathrm{H}$ atoms, $\mathrm{Me}_{2} \mathrm{NH}_{2}$ cations and free DMF molecules are omitted for clarity. (c) Powder X-ray diffraction patterns of $\mathrm{Eu}\left(\mathrm{BDC}-\mathrm{NH}_{2}\right), \mathrm{Tb}\left(\mathrm{BDC}-\mathrm{NH}_{2}\right)$ and $\mathrm{Gd}\left(\mathrm{BDC}-\mathrm{NH}_{2}\right)$.

confirmed by similarities between the simulated and measured PXRD patterns (Fig. 1(c)). By replacing the metal salt with $\mathrm{Tb}\left(\mathrm{NO}_{3}\right)_{3} \cdot 6 \mathrm{H}_{2} \mathrm{O}$ or $\mathrm{Gd}\left(\mathrm{NO}_{3}\right)_{3} \cdot 6 \mathrm{H}_{2} \mathrm{O}$ in the same reaction mixture, the isostructural MOFs $\mathrm{Tb}\left(\mathrm{BDC}-\mathrm{NH}_{2}\right)$ and $\mathrm{Gd}\left(\mathrm{BDC}-\mathrm{NH}_{2}\right)$ were obtained as expected, respectively (Fig. 1(c)).

Single-crystal X-ray diffraction analysis indicates that $\mathrm{Eu}\left(\mathrm{BDC}-\mathrm{NH}_{2}\right)$ crystallizes in the cubic $F m \overline{3} m$ space group. The crystal structure of $\mathrm{Eu}\left(\mathrm{BDC}-\mathrm{NH}_{2}\right)$ is shown in Fig. 1. In $\mathrm{Eu}\left(\mathrm{BDC}-\mathrm{NH}_{2}\right)$, each $\mathrm{Eu}^{3+}$ ion is coordinated by four oxygen atoms from four $\mu_{3}-\mathrm{OH}$ groups, four carboxyl oxygen atoms from the four $\mathrm{BDC}-\mathrm{NH}_{2}{ }^{2-}$ ligands, and one terminal water molecule. The nine-coordinated $\mathrm{Eu}^{3+}$ ions are further bridged via $\mu_{3}-\mathrm{OH}$ and deprotonated carboxylate groups in a bis-monodentate fashion to form hexanuclear europium clusters, $\left[\mathrm{Eu}_{6}\left(\mu_{3}-\right.\right.$ $\left.\mathrm{OH})_{8}\left(\mathrm{CO}_{2}\right)_{12}\right]$ (Fig. 1(a)). These hexanuclear clusters serve as 12-connected secondary building units (SBUs) and each of them is connected with twelve other clusters through $\mathrm{BDC}-\mathrm{NH}_{2}{ }^{2-}$ linkers to generate a $3 \mathrm{D}$ coordination network with fcu topology (Fig. 1(b)). The framework structure of $\mathrm{Eu}\left(\mathrm{BDC}-\mathrm{NH}_{2}\right)$ contains octahedral and tetrahedral pores with the diameter of about 7.3 and $4.1 \AA$, respectively, which are filled with charge balancing cations $\mathrm{Me}_{2} \mathrm{NH}_{2}{ }^{+}$and DMF molecules. Nitrogen adsorption measurement performed on the methanol-exchanged $\mathrm{Eu}\left(\mathrm{BDC}-\mathrm{NH}_{2}\right)$ at $77 \mathrm{~K}$ shows fully reversible type I isotherms (Fig. S3, Supplementary information), indicative of a porous material with permanent microporosity. The Brunauer-Emmett-Teller (BET) surface area is estimated to be $671.3 \mathrm{~m}^{2} \cdot \mathrm{g}^{-1}$. Because of the large pore capacity, organic solvent or water molecules can easily access in the pores and the original DMF molecules are exchanged. TGA thermogram of water-exchanged $\mathrm{Eu}\left(\mathrm{BDC}-\mathrm{NH}_{2}\right)$ shows that the maximum water uptake is about $0.16 \mathrm{Kg} \cdot \mathrm{Kg}^{-1} \cdot \mathrm{Eu}\left(\mathrm{BDC}-\mathrm{NH}_{2}\right)$ can retain its crystallinity and unchanged structures in common organic solvents such as THF, ethanol, acetone, acetonitrile and so on, as evidenced by the measured PXRD patterns of soaked $\mathrm{Eu}\left(\mathrm{BDC}-\mathrm{NH}_{2}\right)$ samples in different solvents (Fig. S4, Supplementary information).

The stability of $\mathrm{Eu}\left(\mathrm{BDC}-\mathrm{NH}_{2}\right)$ in water was evaluated by testing the amount of dissolved ligand in supernatant of $\mathrm{Eu}\left(\mathrm{BDC}-\mathrm{NH}_{2}\right)$ aqueous suspension $(10 \mathrm{~mL}, 10$ $\mathrm{mg} \cdot \mathrm{mL}^{-1}$ ) with the elapse of time by UV absorption spectrum. As shown in Fig. 2(a), with the increase of soaking time, the amount of dissolved ligand increased rapidly at the beginning, and the increase rate slowed down after 1 day, and then reached the equilibrium after about 3 days with the equilibrium concentration about $5.51 \times 10^{-4}$ $\mathrm{mol} \cdot \mathrm{L}^{-1}$. According to the molecular formula of $\mathrm{Eu}(\mathrm{BDC}$ $\mathrm{NH}_{2}$ ), the dissolved $\mathrm{Eu}\left(\mathrm{BDC}-\mathrm{NH}_{2}\right)$ was calculated to be $2.50 \%$ of the original. More interestingly, the undissolved portion of $\mathrm{Eu}\left(\mathrm{BDC}-\mathrm{NH}_{2}\right)$ can maintain its framework and porosity intact. The measured PXRD patterns of $\mathrm{Eu}\left(\mathrm{BDC}-\mathrm{NH}_{2}\right)$ soaked in water for $48 \mathrm{~h}$ at room temperature show retained crystallinity and unchanged structures (Fig. S5, Supplementary information). This retention of framework and porosity in water was further authenticated by the preservation of the original apparent BET surface area with a slight decrease, as evidenced by the conserved characteristics of the nitrogen adsorption isotherm (Fig. 2(b)). All of the above results indicate a suitable stability of aqueous $\mathrm{Eu}\left(\mathrm{BDC}-\mathrm{NH}_{2}\right)$ suspension at room temperature.

The excitation spectra of $\mathrm{Eu}\left(\mathrm{BDC}-\mathrm{NH}_{2}\right)$ displays an intense and broad band with a maximum at around 375 $\mathrm{nm}$, which is ascribed to the $\pi-\pi^{*}$ electron transition of BDC- $\mathrm{NH}_{2}{ }^{2-}$ ligands (Figs. S6-S9, Supplementary information). Upon excited at $375 \mathrm{~nm}$, the solid sample of 

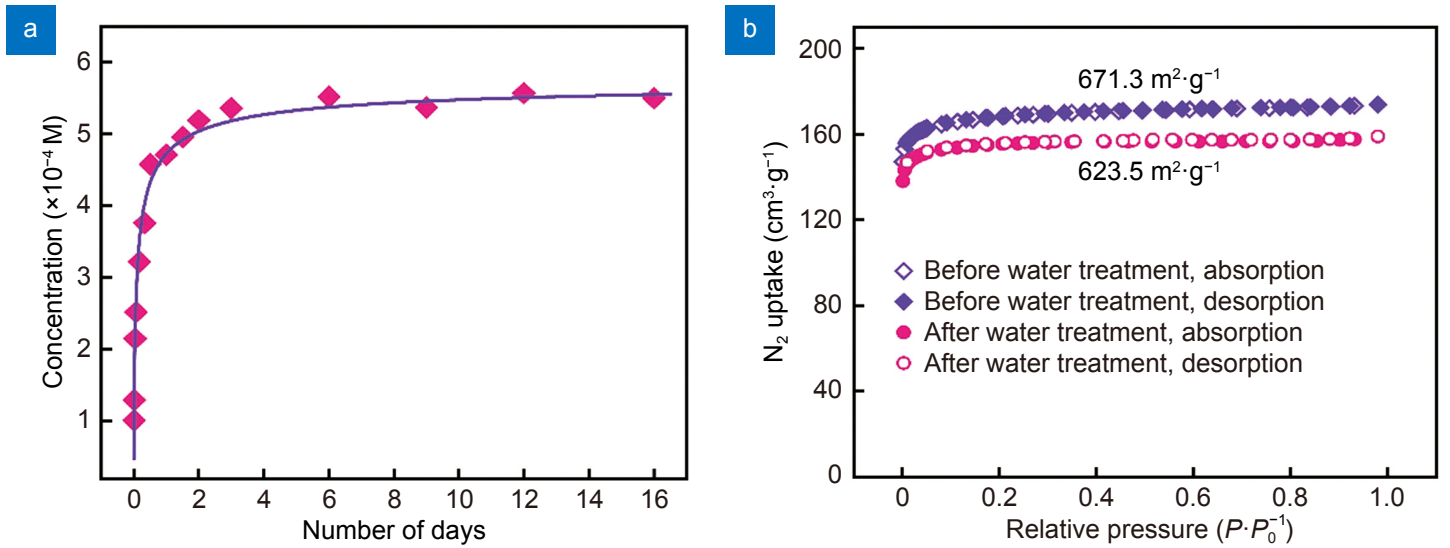

Fig. 2 I (a) The concentration of dissolved ligand $\mathrm{H}_{2} \mathrm{BDC}-\mathrm{NH}_{2}$ in $\mathrm{Eu}\left(\mathrm{BDC}-\mathrm{NH}_{2}\right)$ suspension at different time. (b) $\mathrm{N}_{2}$ sorption isotherms of Eu(BDC$\mathrm{NH}_{2}$ ) before (red) and after (blue) being treated with water at $77 \mathrm{~K}$. Solid symbols: adsorption, open symbols: desorption.

$\mathrm{Eu}\left(\mathrm{BDC}-\mathrm{NH}_{2}\right)$ exhibits characteristic emission peaks of $\mathrm{Eu}^{3+}$ ions at $579,594,614,653$, and $700 \mathrm{~nm}$, which can be ascribed to the ${ }^{5} \mathrm{D}_{0} \rightarrow{ }^{7} \mathrm{~F}_{J}(J=0,1,2,3$ and 4$)$ transitions, respectively (Fig. 3(a)). It is worth noting that no apparent residual emission from the $\mathrm{BDC}-\mathrm{NH}_{2}{ }^{2-}$ ligand was observed in solid-state $\mathrm{Eu}\left(\mathrm{BDC}-\mathrm{NH}_{2}\right)$, indicating that the excitation energy absorbed by the ligands is efficiently transferred to the $\mathrm{Eu}^{3+}$ ions. Similarly, the suspension of $\mathrm{Eu}\left(\mathrm{BDC}-\mathrm{NH}_{2}\right)$ in THF exhibits the strong characteristic emission peaks of $\mathrm{Eu}^{3+}$ ions (Fig. 3(b)). However, the characteristic $4 \mathrm{f}-4 \mathrm{f}$ transitions of $\mathrm{Eu}^{3+}$ ions are almost totally quenched while the ligand-based luminescence centered at $430 \mathrm{~nm}$ is drastically enhanced when $\mathrm{Eu}\left(\mathrm{BDC}-\mathrm{NH}_{2}\right)$ is suspended in water (Fig. 3(c)).

Encouraged by the changed luminescence of $\mathrm{Eu}$ (BDC$\mathrm{NH}_{2}$ ) under water treatment, we sought to explore its potential for multicolor luminescence through tuning the content of water. As a proof-of-concept experiment, the in situ emission spectra were monitored with the piece by piece addition of water in $2 \mathrm{~mL}$ of dry organic solvents (THF, ethanol, acetone, and acetonitrile) where $\mathrm{Eu}\left(\mathrm{BDC}-\mathrm{NH}_{2}\right)(1 \mathrm{mg})$ was suspended. As shown in Fig. $4(\mathrm{a}, \mathrm{b})$, the luminescence intensity of $\mathrm{BDC}-\mathrm{NH}_{2}{ }^{2-}$ lig- ands at $430 \mathrm{~nm}$ substantially increases with the addition of water in THF from 0 to $5 \mathrm{vol} \%$, concomitant with a dramatic decrease of the emissions of $\mathrm{Eu}^{3+}$ ions when excited at $375 \mathrm{~nm}$. The luminescence intensity ratio between ligand $(430 \mathrm{~nm})$ and $\mathrm{Eu}^{3+}$ ion $(614 \mathrm{~nm})$ in $\mathrm{Eu}\left(\mathrm{BDC}-\mathrm{NH}_{2}\right)$ can be correlated well with the water content in THF by a linearly relationship of

$$
I_{430} / I_{614}=0.3919 c+0.0121
$$

with correlation coefficient 0.9975 over a wide range from 0 to 5 vol\% (Fig. 4(c)), where $I_{430}$ and $I_{614}$ are the luminescence intensity of ligand and $\mathrm{Eu}^{3+}$, respectively; $c$ is the water content in THF (vol\%). As shown in Fig. S10 (Supplementary information), $\mathrm{Eu}\left(\mathrm{BDC}-\mathrm{NH}_{2}\right.$ ) can work even in the ultra-low water content range such as $0-0.1$ vol\% and $0-1$ vol\%. Similar trends of emission spectral changes and linear calibration curves were also observed upon adding water to the suspension of $\mathrm{Eu}\left(\mathrm{BDC}-\mathrm{NH}_{2}\right)$ in ethanol, acetone, and acetonitrile (Figs. S11, S12 and S13, Supplementary information). In addition, the fluorescence titrations were also performed using 0.5 and 1.5 $\mathrm{mg}$ of $\mathrm{Eu}\left(\mathrm{BDC}-\mathrm{NH}_{2}\right)$ as fluorescent indicator, respectively. The results indicate that the luminescence
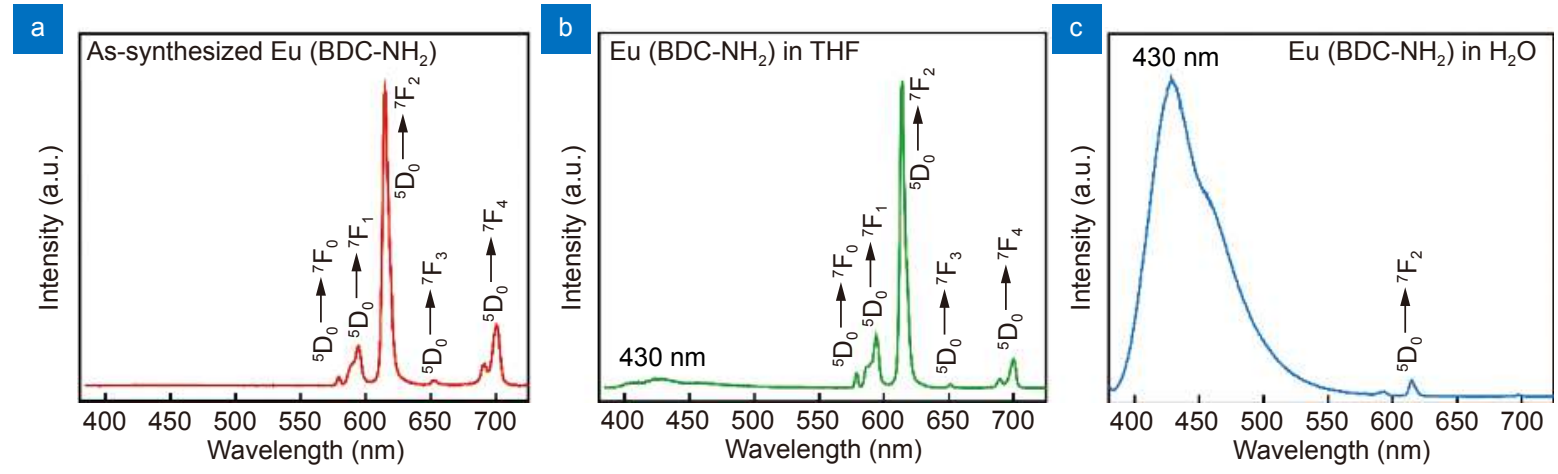

Fig. 3 | Emission spectra of Eu(BDC-NH $\mathrm{NH}_{2}$ in the solid state (a) suspended in THF (b) and in water (c) excited at $375 \mathrm{~nm}$. 

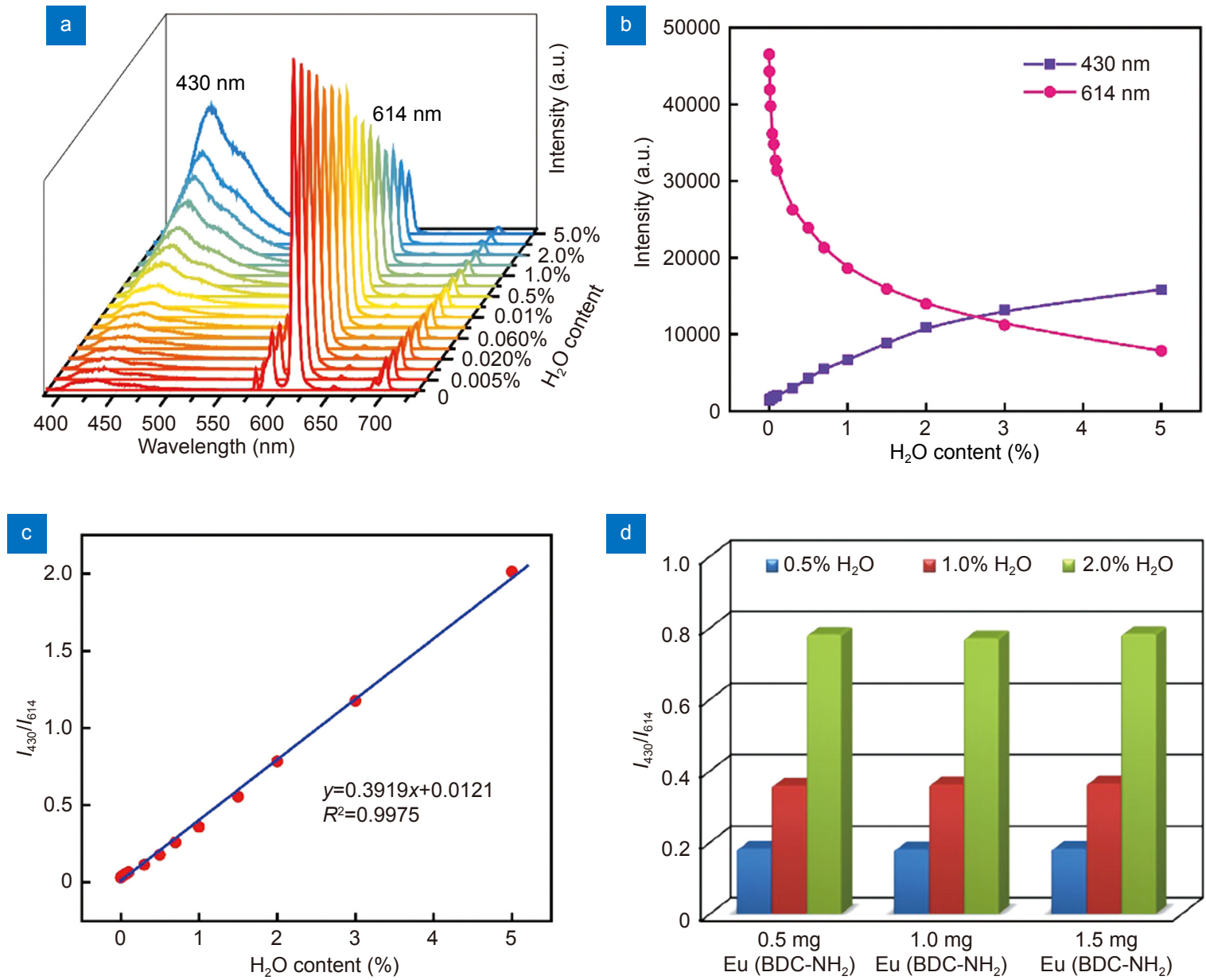

Fig. 4 | (a) Emission spectra of $\mathrm{Eu}\left(\mathrm{BDC}-\mathrm{NH}_{2}\right)$ suspended in THF with different water content excited at $375 \mathrm{~nm}$. (b) Intensities of ligand luminescence and ${ }^{5} \mathrm{D}_{0} \rightarrow{ }^{7} \mathrm{~F}_{2}$ transition of $\mathrm{Eu}\left(\mathrm{BDC}-\mathrm{NH}_{2}\right)$ in the presence of various content of water. (c) The relationship of luminescence intensity ratio $\left(I_{430} / /_{614}\right)$ and water content. (d) Luminescence intensity ratio $\left(I_{430} / /_{614}\right)$ measured in $\mathrm{THF} / \mathrm{H}_{2} \mathrm{O}$ mixture with given water content $(0.5,1$ and 2 vol\%) using different amounts of $\mathrm{Eu}\left(\mathrm{BDC}-\mathrm{NH}_{2}\right)(0.5,1.0$ and $1.5 \mathrm{mg})$.

intensity ratio $\left(I_{430} / I_{614}\right)$ only depends on the water content while independent of the amount of $\mathrm{Eu}\left(\mathrm{BDC}-\mathrm{NH}_{2}\right)$ used for multicolor luminescence (Fig. 4(d)), thus demonstrating that $\mathrm{Eu}\left(\mathrm{BDC}-\mathrm{NH}_{2}\right)$ is an excellent anticounterfeiting matrix and does not require additional processing steps for reading out multicolor information. To further demonstrate the versatility of this strategy, similar experiments were also performed using the isostructural MOF $\mathrm{Tb}\left(\mathrm{BDC}-\mathrm{NH}_{2}\right)$ as a sensor. As expected, the luminescence intensity ratio between the ligand and $\mathrm{Tb}^{3+}$ is also linearly dependent on the water content from 0 to 5 vol\% in THF (Fig. S14, Supplementary information).

The multicolor luminescence of designed MOFs $\mathrm{Eu}\left(\mathrm{BDC}-\mathrm{NH}_{2}\right)$ under external water treatment for multilevel information anti-counterfeiting is feasible, but the stability of $\mathrm{Eu}\left(\mathrm{BDC}-\mathrm{NH}_{2}\right)$ is also necessary because the anti-counterfeiting tags on the product always face various types of environment. Therefore, it is worth men- tioning that the photostability of $\mathrm{Eu}\left(\mathrm{BDC}-\mathrm{NH}_{2}\right)$ is especially outstanding (Fig. S15, Supplementary information) and the fluorescent response toward water is immediate. As is shown in Fig. S16, it takes just $12 \mathrm{~s}$ of $\mathrm{Eu}^{3+}$ emission to accomplish $95 \%$ of the overall luminescent intensity variation, and ligand luminescence increases steeply after the addition of water, suggesting the very fast and real-time responsive ability of $\mathrm{Eu}\left(\mathrm{BDC}-\mathrm{NH}_{2}\right)$. More importantly, the responsive ability of $\mathrm{Eu}(\mathrm{BDC}$ $\mathrm{NH}_{2}$ ) can be easily recovered and regenerated by simply removing the dissolved part with organic solvents. As shown by the repeatability experiment (Fig. S17, Supplementary information) and PXRD (Fig. S18, Supplementary information), the frameworks of $\mathrm{Eu}\left(\mathrm{BDC}-\mathrm{NH}_{2}\right)$ are also intact and the luminescent intensity ratio is fully reversible without significant hysteresis after four consecutive of detection cycles.

Due to the different luminescent colors and opposite 
intensity changes of ligand and $\mathrm{Eu}^{3+}$ ion, the $\mathrm{Eu}(\mathrm{BDC}$ $\mathrm{NH}_{2}$ ) sensor exhibits a prominent luminescence color change, which is almost linearly tuned from red to blue with the addition of water in THF. Figure 5(a) shows the emission colors of $\mathrm{Eu}\left(\mathrm{BDC}-\mathrm{NH}_{2}\right)$ in Commission Internacionale de L'Eclairage (CIE) chromaticity diagram transformed from the corresponding water-dependent emission spectra, which changes from $(0.562,0.295)$ to $(0.184,0.080)$ when the water content increases from 0 vol\% to $5 \mathrm{vol} \%$. It can be found that the color evolution strongly depends on the water content and even a slight increase of the water content can cause obvious color change in THF and EtOH (Fig. 5(b, c)). Especially, different water content is used as a key to read anti-counterfeiting information under specific color, which greatly improves the security of anti-counterfeiting materials. Meanwhile, such a significant color switching can be easily observed by the naked eye and captured by a single CCD camera, thus enabling us to directly visualize the water content in various organic solvents. Above results demonstrate that $\mathrm{Eu}\left(\mathrm{BDC}-\mathrm{NH}_{2}\right)$ is an excellent candidate for anti-counterfeiting materials with real-time, robust and reusable multicolor luminescence by simple water treatment, thus providing a significant advantage over the traditional anti-counterfeiting tags.

Such a highly sensitive luminescence response of $\mathrm{Ln}\left(\mathrm{BDC}-\mathrm{NH}_{2}\right)$ toward water is mainly due to the following three reasons: 1) hydrogen-bond interaction between $-\mathrm{NH}_{2}$ group and water molecules; 2) quenching of $\mathrm{Ln}^{3+}$ emission by the effect of $\mathrm{O}-\mathrm{H}$ oscillators, which is universal and acknowledged and 3) the changed energy transfer process of $\mathrm{Ln}\left(\mathrm{BDC}-\mathrm{NH}_{2}\right)$.

Among these reasons, the quenching of $\mathrm{Ln}^{3+}$ emission caused by $\mathrm{O}-\mathrm{H}$ oscillators is the dominant one. This is because $\mathrm{BDC}-\mathrm{NH}_{2}$ possesses hydrophilic active sites $-\mathrm{NH}_{2}$, thus water molecules enter cages easily, and meanwhile, the introduction of water results in the increase of nonradiative decay pathways (O-H oscillators) that prevents radiative relaxation (emission), accounting for the quenching of $\mathrm{Ln}^{3+}$ emission ${ }^{34,35}$. On the other hand, we speculate that there may be another mechanism. The energy levels of the ligands and $\mathrm{Eu}^{3+}$ ions of $\mathrm{Eu}\left(\mathrm{BDC}-\mathrm{NH}_{2}\right)$ with water present and absent were further investigated. According to antenna effect theory, the energy level of triplet state $\left(T_{1}\right)$ of ligand has to be at about $2500-4000 \mathrm{~cm}^{-1}$ above the emissive $4 \mathrm{f} \mathrm{level} \mathrm{of} \mathrm{Eu}^{3+}$ $\left({ }^{5} \mathrm{D}_{0}, 17300 \mathrm{~cm}^{-1}\right)$ in order to efficiently sensitize $\mathrm{Eu}^{3+}$ emission, otherwise the energy back-transfer becomes
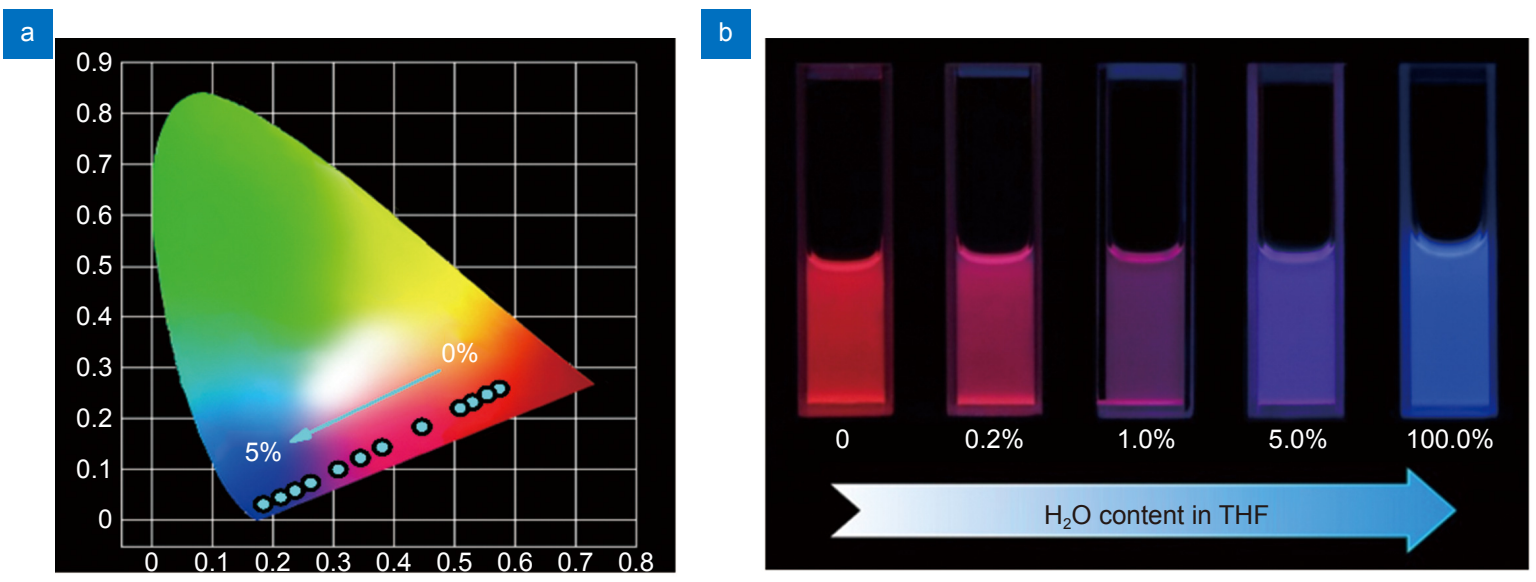

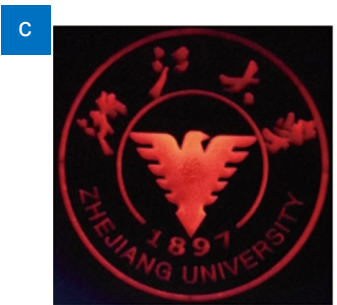

0

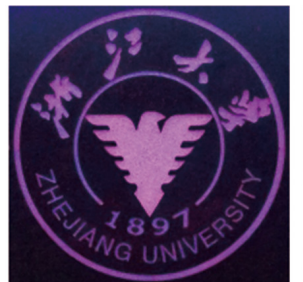

$0.2 \%$

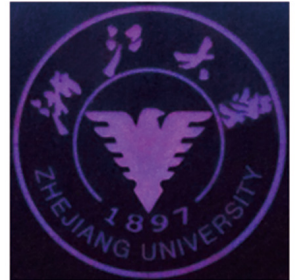

$1.0 \%$

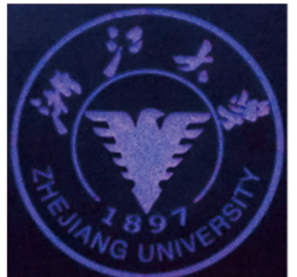

$5.0 \%$

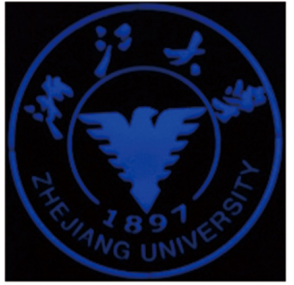

$100.0 \%$

\section{$\mathrm{H}_{2} \mathrm{O}$ content in $\mathrm{EtOH}$}

Fig. 5 | (a) CIE chromaticity coordinates of the luminescence color of Eu(BDC-NH $\left.\mathrm{N}_{2}\right)$ in THF with different water content $(c=0,0.01,0.04,0.1$, $0.3,0.5,0.7,1,1.5,2,3$, and 5 vol\%, respectively). Photographs of Eu(BDC-NH 2$)$ in (b) THF and (c) EtOH with different water content excited at $365 \mathrm{~nm}$. 

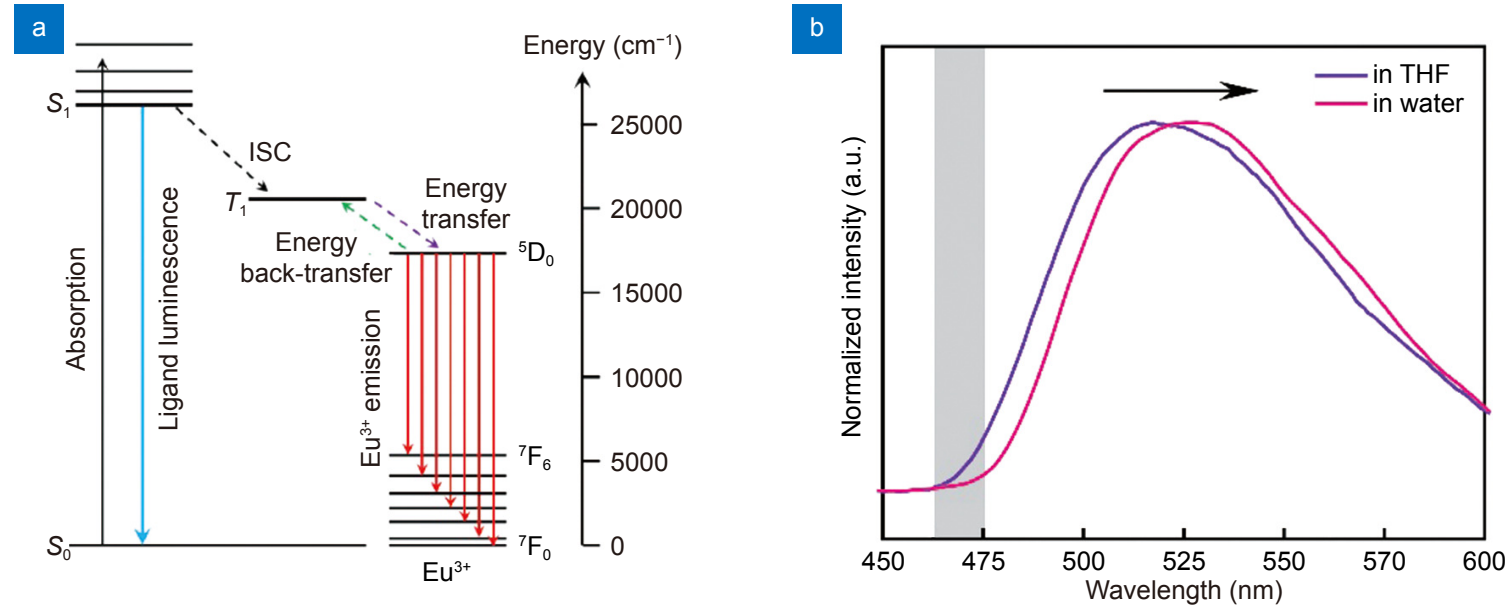

Fig. 6 | (a) Schematic representation of energy transfer process in $\mathrm{Eu}\left(\mathrm{BDC}-\mathrm{NH}_{2}\right)$. (b) Phosphorescence spectra of Gd(BDC-NH $\left.\mathrm{H}_{2}\right)$ at $77 \mathrm{~K}$ excited at $375 \mathrm{~nm}$ in frozen THF and water.

possible and the remaining ligand fluorescence in combination with the $\mathrm{Eu}^{3+}$-centered emission can be simultaneously observed (Fig. 6(a) $)^{36,37}$. The lowest energy level of $\mathrm{Gd}^{3+}\left(32200 \mathrm{~cm}^{-1}\right)$ is well above the $S_{1}$ and $T_{1}$ levels of $\mathrm{BDC}-\mathrm{NH}_{2}$, and therefore, the triplet energy level of the corresponding ligands can be obtained from the phosphorescence spectra of the $\mathrm{Gd}\left(\mathrm{BDC}-\mathrm{NH}_{2}\right)$. Based on the phosphorescence spectra of $\mathrm{Gd}\left(\mathrm{BDC}-\mathrm{NH}_{2}\right)$ at 77 $\mathrm{K}$ in frozen solvents, the $T_{1}$ level of $\mathrm{BDC}-\mathrm{NH}_{2}{ }^{2-}$ ligand in THF was calculated to be $21277 \mathrm{~cm}^{-1}$ while decreased to $20833 \mathrm{~cm}^{-1}$ in water (Fig. 6(b)), which may be attributed to the hydrogen-bond interaction between $-\mathrm{NH}_{2}$ group of BDC- $\mathrm{NH}_{2}{ }^{2-}$ ligands and water molecules. Consequently, upon increasing the water content in THF, the hydrogen-bond interaction between $-\mathrm{NH}_{2}$ group and water is promoted and the $\mathrm{BDC}-\mathrm{NH}_{2}{ }^{2-}$ ligand with low $T_{1}$ level is dominant, thus enhancing the energy backtransfer probability from $\mathrm{Eu}^{3+}$ ion to ligand. As a result, the opposite intensity variation of $\mathrm{Eu}^{3+}$ emission and ligand emission make the intensity ratio more sensitive to water, thus enhancing the detection efficiency. The fluorescence lifetimes of $\mathrm{Eu}\left(\mathrm{BDC}-\mathrm{NH}_{2}\right)$ in THF and $\mathrm{EtOH}$ with different water content were monitored at 430 and $614 \mathrm{~nm}$. The lifetime of ${ }^{5} \mathrm{D}_{0}\left(\mathrm{Eu}^{3+}\right)$ is reduced by the addition of water, whereas the lifetime of ligand-based emission at $430 \mathrm{~nm}$ increases (Figs. S19 and S20, Supplementary information). This is well consistent with the proposed energy back-transfer mechanism.

\section{Conclusion}

In summary, we have successfully illustrated a proof of concept for real-time and multicolor luminescence under simple water treatment in organic solvents using a lanthanide $\mathrm{MOF} \mathrm{Eu}\left(\mathrm{BDC}-\mathrm{NH}_{2}\right)$. Due to the unique re- sponsive mechanism based on increased nonradiative decay pathways and $\mathrm{Eu}^{3+}$-to-ligand energy back transfer process, the ligand-based luminescence in $\mathrm{Eu}(\mathrm{BDC}$ $\mathrm{NH}_{2}$ ) significantly enhanced while the $\mathrm{Eu}^{3+}$ emission decreased with the addition of water content. Accordingly, the synergistic luminescence of $\mathrm{Eu}\left(\mathrm{BDC}-\mathrm{NH}_{2}\right)$ from ligand and $\mathrm{Eu}^{3+}$ emissive centers exhibits a broad span range in CIE chromaticity coordinates, resulting in multicolor luminescence in visible range. More importantly, the different emission colors obtained by water treatment correspond to specific water content, which can be used as an encryption key for high-level anti-counterfeiting tags. Meanwhile, the variable luminescence color makes $\mathrm{Eu}\left(\mathrm{BDC}-\mathrm{NH}_{2}\right)$ have excellent potential for in situ visualizing the multicolor information in organic solvents straightforwardly. The strategy we report here would open a new avenue to develop multicolor luminescent MOFs under simple external stimuli for high-level anti-counterfeiting and stimulate more applied research.

\section{References}

1. Ren W, Lin GG, Clarke C, Zhou JJ, Jin DY. Optical nanomaterials and enabling technologies for high-security-level anticounterfeiting. Adv Mater 32, 1901430 (2020).

2. Staake $T$, Thiesse F, Fleisch $E$. The emergence of counterfeit trade: a literature review. Eur J Mark 43, 320-349 (2009).

3. Li RM, Zhang YT, Tan J, Wan JX, Guo J et al. Dual-mode encoded magnetic composite microsphere based on fluorescence reporters and raman probes as covert tag for anticounterfeiting applications. ACS Appl Mater Interfaces 8, 9384-9394 (2016).

4. Prime EL, Solomon DH. Australia's plastic banknotes: fighting counterfeit currency. Angew Chem Int Ed 49, 3726-3736 (2010).

5. Yao WJ, Tian QY, Wu W. Tunable emissions of upconversion fluorescence for security applications. Adv Opt Mater 7, 1801171 (2019). 
6. Ji XF, Wu RT, Long LL, Ke XS, Guo CX et al. Encoding, reading, and transforming information using multifluorescent supramolecular polymeric hydrogels. Adv Mater 30, 1705480 (2018).

7. Arppe R, Sørensen TJ. Physical unclonable functions generated through chemical methods for anti-counterfeiting. Nat Rev Chem 1, 0031 (2017).

8. Zhang C, Yang L, Zhao J, Liu BH, Han MY et al. White - light emission from an integrated upconversion nanostructure: toward multicolor displays modulated by laser power. Angew Chem Int Ed 54, 11531-11535 (2015).

9. Lu YQ, Zhao JB, Zhang R, Liu YJ, Liu DM et al. Tunable lifetime multiplexing using luminescent nanocrystals. Nat Photonics 8, 32-36 (2014).

10. Chen GY, Damasco J, Qiu HL, Shao W, Ohulchanskyy TY et al. Energy-cascaded upconversion in an organic dye-sensitized core/shell fluoride nanocrystal. Nano Lett 15, 7400-7407 (2015).

11. Zhou JJ, Wen SH, Liao JY, Clarke C, Tawfik SA et al. Activation of the surface dark-layer to enhance upconversion in a thermal field. Nat Photonics 12, 154-158 (2018)

12. Zhang JC, Pan C, Zhu YF, Zhao LZ, He HW et al. Achieving thermo-mechano-opto-responsive bitemporal colorful luminescence via multiplexing of dual lanthanides in piezoelectric particles and its multidimensional anticounterfeiting. Adv Mater 30, 1804644 (2018).

13. Cai GR, Jiang HL. A modulator-induced defect-formation strategy to hierarchically porous metal-organic frameworks with high stability. Angew Chem Int Ed 56, 563-567 (2017).

14. Chen ZJ, Li PH, Anderson R, Wang XJ, Zhang X et al. Balancing volumetric and gravimetric uptake in highly porous materials for clean energy. Science 368, 297-303 (2020).

15. Islamoglu T, Chen ZJ, Wasson MC, Buru CT, Kirlikovali KO et al. Metal-organic frameworks against toxic chemicals. Chem Rev 120, 8130-8160 (2020).

16. Lee S, Kapustin EA, Yaghi OM. Coordinative alignment of molecules in chiral metal-organic frameworks. Science $\mathbf{3 5 3}$, 808-811 (2016).

17. Li J, Wang XX, Zhao GX, Chen CL, Chai ZF et al. Metal-organic framework-based materials: superior adsorbents for the capture of toxic and radioactive metal ions. Chem Soc Rev 47, 2322-2356 (2018).

18. Li P, Vermeulen NA, Malliakas CD, Gómez-Gualdrón DA, Howarth AJ et al. Bottom-up construction of a superstructure in a porous uranium-organic crystal. Science 356, 624-627 (2017).

19. Wang B, Zhang X, Huang HL, Zhang ZJ, Yildirim T et al. A microporous aluminum-based metal-organic framework for high methane, hydrogen, and carbon dioxide storage. Nano Res 14, 507-511 (2021).

20. Yu BX, Ye G, Chen J, Ma SQ. Membrane-supported 1D MOF hollow superstructure array prepared by polydopamine-regulated contra-diffusion synthesis for uranium entrapment. Environ Pollut 253, 39-48 (2019).

21. Zhang X, Lin RB, Wang J, Wang B, Liang B et al. Optimization of the pore structures of MOFs for record high hydrogen volumetric working capacity. Adv Mater 32, 1907995 (2020).

22. Yuan HY, Tao JF, Li NX, Karmakar A, Tang CH et al. On - chip tailorability of capacitive gas sensors integrated with metal-organic framework films. Angew Chem Int Ed 58, 14089-14094 (2019).

23. Yao YN, Gao ZH, Lv YC, Lin XQ, Liu YY et al. Heteroepitaxial growth of multiblock Ln-MOF microrods for photonic barcodes.
Angew Chem Int Ed 58, 13803-13807 (2019).

24. Kim H, Yang S, Rao SR, Narayanan S, Kapustin EA et al. Water harvesting from air with metal-organic frameworks powered by natural sunlight. Science 356, 430-434 (2017).

25. Nguyen HL, Hanikel N, Lyle SJ, Zhu CH, Proserpio DM et al. A porous covalent organic framework with voided square grid topology for atmospheric water harvesting. J Am Chem Soc 142, 2218-2221 (2020).

26. Ma D, Li P, Duan XY, Li JZ, Shao PP et al. A hydrolytically stable vanadium(IV) metal-organic framework with photocataIytic bacteriostatic activity for autonomous indoor humidity control. Angew Chem Int Ed 59, 3905-3909 (2020).

27. Burtch NC, Jasuja H, Walton KS. Water stability and adsorption in metal-organic frameworks. Chem Rev 114, 10575-10612 (2014).

28. Hao JN, Li YS. Concurrent modulation of competitive mechanisms to design stimuli-responsive Ln-MOFs: a light-operated dual-mode assay for oxidative DNA damage. Adv Funct Mater 29, 1903058 (2019)

29. Zhao NS, Li LJ, Song XZ, Zhu M, Hao ZM et al. Lanthanide ion codoped emitters for tailoring emission trajectory and temperature sensing. Adv Funct Mater 25, 1463-1469 (2015).

30. Li ZQ, Wang GN, Ye YX, Li B, Li HR et al. Loading photochromic molecules into a luminescent metal-organic framework for information anticounterfeiting. Angew Chem Int Edit 58, 18025-18031 (2019).

31. Razavi SAA, Morsali A. Linker functionalized metal-organic frameworks. Coordin Chem Rev 388, 213023 (2019).

32. Guillerm V, Weseliński ŁJ, Belmabkhout Y, Cairns AJ, D'Elia V et al. Discovery and introduction of a $(3,18)$-connected net as an ideal blueprint for the design of metal-organic frameworks. Nat Chem 6, 673-680 (2014).

33. Xue DX, Belmabkhout $\mathrm{Y}$, Shekhah $\mathrm{O}$, Jiang $\mathrm{H}$, Adil $\mathrm{K}$ et al. Tunable rare earth fcu-MOF platform: access to adsorption kinetics driven gas/vapor separations via pore size contraction. $J$ Am Chem Soc 137, 5034-5040 (2015).

34. Yu Y, Ma JP, Dong YB. Luminescent humidity sensors based on porous $\mathrm{Ln}^{3+}$-MOFs. CrystEngComm 14, 7157-7160 (2012).

35. Yu L, Zheng QT, Wang H, Liu CX, Huang XQ et al. Double-color lanthanide metal-organic framework based logic device and visual ratiometric fluorescence water microsensor for solid pharmaceuticals. Anal Chem 92, 1402-1408 (2020).

36. Li L, Zhu YL, Zhou XH, Brites CDS, Ananias D et al. Visible light excited luminescent thermometer based on single lanthanide organic frameworks. Adv Funct Mater 26, 8677-8684 (2016).

37. Heine J, Müller-Buschbaum K. Engineering metal-based luminescence in coordination polymers and metal-organic frameworks. Chem Soc Rev 42, 9232-9242 (2013).

\section{Acknowledgements}

This work was supported by the National Natural Science Foundation of China (Nos. 52025131, 51632008, 51772268, and 61721005) and Zhejiang Provincial Natural Science Foundation of China (No. LD18E020001).

\section{Competing interests}

The authors declare no competing financial interests.

\section{Supplementary information}

Supplementary information for this paper is available at https://doi.org/10.29026/oea.2021.200063 